Retraction

\title{
Retraction: Das, P. Role of Happiness as a Habitual Process. Proceedings 2017, 1, 232.
}

Proceedings Editorial Office

St. Alban-Anlage 66, 4052 Basel, Switzerland

* Correspondence: proceedings@mdpi.com

Published: 28 August 2018

The paper [1] was not ready for final publication and was put online in error. The paper will be marked as retracted. We apologize to the author and readers for any inconvenience.

\section{Reference}

1. Das, P. Role of Happiness as a Habitual Process. Proceedings 2017, 1, 232.

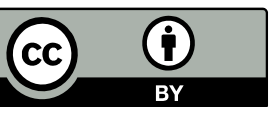

(C) 2018 by the authors. Licensee MDPI, Basel, Switzerland. This article is an open access article distributed under the terms and conditions of the Creative Commons Attribution (CC BY) license (http://creativecommons.org/licenses/by/4.0/). 